\title{
Prospects for Health Impact Assessment in the United States: New and Improved Environmental Impact Assessment or Something Different?
}

\author{
Brian L. Cole, Michelle Wilhelm, Peter V. Long, \\ Jonathan E. Fielding, and Gerald Kominski \\ University of California, Los Angeles \\ Hal Morgenstern \\ University of Michigan
}

\begin{abstract}
Health impact assessment (HIA) has been advanced as a means of bringing potential health impacts to the attention of policy makers, particularly in sectors where health impacts may not otherwise be considered. This article examines lessons for HIA in the United States from the related and relatively well-developed field of environmental impact assessment (EIA). We reviewed the EIA literature and conducted twenty phone interviews with EIA professionals. Successes of EIA cited by respondents included integration of environmental goals into decision making, improved planning, and greater transparency and public involvement. Reported shortcomings included the length and complexity of EIA documents, limited and adversarial public participation, and an emphasis on procedure over substance. Presently, EIAs consider few, if any, health outcomes. Respondents differed on the prospects for HIA. Most agreed that HIA could contribute to EIA in several areas, including assessment of cumulative impacts and impacts to environmental justice. Reasons given for not incorporating HIA into EIA were uncertainties about interpreting estimated health impacts, that EIA documents would become even longer and more complicated, and that HIA would gain little from the procedural and legal emphasis in EIA. We conclude that for HIA to advance, whether as part of or separate from EIA, well-formulated methodologies need to be developed and tested in real-world situations. When possible, HIA should build on the methods that have been utilized successfully in EIA. The most fruitful avenue is demonstration projects that test, refine, and demonstrate different methods and models to maximize their utility and acceptance.
\end{abstract}

Health impact assessment (HIA) has been advanced in a number of different nations and by the World Health Organization (WHO) as a means to facilitate the consideration of potential health consequences of proposed policies (World Health Organization 1999; Ison 2000; Northern and York 
Public Health Observatory 2001), particularly outside the health sector where potential health effects may not be fully recognized (First International Conference on Health Promotion 1986). A core tenet of HIA is that policy makers, stakeholders, and the public can benefit from clearly communicated information generated from a balanced, formal, and systematic analysis of potential health impacts of proposed projects, policies, or programs.

From Hippocrates several thousand years ago to Rudolf Virchow over one hundred years ago, it has long been recognized that social and economic conditions, and the governmental policies that affect them, play a significant role in determining people's health (Tesh 1988). More recently, a number of initiatives of the World Health Organization, including the Alma Ata Declaration, the Ottawa Charter on Health Promotion, and the Healthy Cities Movement, have emphasized the intersectoral influences of health. Operationalizing this conceptual model to determine likely health effects of health promotion activities, however, has been problematic. HIA offers one potential mechanism for successfully coordinating intersectoral action for improving health.

This article explores some of the issues influencing the feasibility of HIA in the unique legislative and legal context of the United States, drawing on what can be learned from the related field of environmental impact assessment (EIA). While EIA usually stops short of evaluating potential health outcomes, much of the impetus for EIA comes from concerns about protecting human health (Caldwell 1998). In its more than thirty years of practice in the United States, EIA has evolved greatly as it has had to confront numerous methodological, bureaucratic, and legal challengesmany of which HIA must also confront.

Health impact assessment is a formal, systematic analysis to prospectively assess the potential health impacts of proposed projects, programs, and policies and communicate this information to policy makers and stakeholders. Several different approaches have been taken in this nascent and rapidly evolving field. In many countries where HIA has been applied, most notably Britain and Sweden, it is seen as a means to increase community participation in decision making on issues that impact health (British Medical Association 1998), much like the community councils promoted in the Healthy Cities Movement (Ashton 1991). In some countries it has been considered an analytic tool to help assess the scientific evidence from which population health impacts can be estimated, for example Germany (Fehr 1999) and New Zealand (Signal and Durham 2000). Primarily, but not exclusively, in countries taking this latter ap- 
proach, HIA has been linked to environmental impact assessment. ${ }^{1}$ Linkages between HIA and EIA have been especially strong in Canada (Health Canada 2000), New Zealand (New Zealand Ministry of Health 1998), Tasmania, Australia (Tasmania Department of Health and Human Services 2002), and Germany (Fehr 1999). Linking HIA and EIA has also been advocated in Britain (British Medical Association 1998) and other nations (Birley 1995; Canter 1998; Sadler 1998; World Bank 1997).

Despite the growing literature worldwide on HIA and moves to formally incorporate it in government decision making in other countries, development of HIA in the United States has been relatively slow. Our review of the National Library of Medicine article database revealed only two HIAs in the peer-reviewed medical or public health journals: (1) an analysis of the potential health impacts of global climate change (Patz et al. 2000) and (2) an analysis of the health impacts of a municipal living wage ordinance by Rajiv Bhatia and Michael Katz (2001). A few other references to HIA in the United States are found in government reports and other gray literature, including American Association of Retired Persons (AARP) et al. 2001, a review and analysis conducted by the Minnesota Health Improvement Project (2002), and the proceedings from the Conference on the Built Environment - Healthy Communities, Healthy Homes, Healthy People convened by the National Institute of Environmental Health Sciences (NIEHS; Srinivasan, O'Fallon, and Dearry 2002). In addition, there are a number of other published analyses that, like HIA, comprehensively examine the health impacts of proposed policies, including Howard Shaffer and David Korn's (2002) analysis of expanded gambling, James Hammitt et al.'s (1999) examination of the health trade-offs resulting from stricter building codes, Rafael Ponce et al.'s (2000) conclusions about tailoring public health messages based on their analysis of the risks and benefits of fish consumption, and the Environmental Protection Agency's (EPA) comparative risk analysis of water treatment options (Rice et al. 1999). Some of these could be seen as HIAs in all but name, while others were not quite full HIAs in that they did not (1) examine the potential effects of a specific policy, program, or project or (2) comprehensively consider a broad range of potential health impacts. For instance, Harvard University's report on the health and environmental

1. This paper uses the term EIA generically. It is both a process and a document for the prospective and systematic assessment of potential environmental impacts stemming from proposed projects, programs, and policies. In reference to NEPA, it includes both environmental impact statements and environmental assessments. More generally, it also includes similar statemandated documents and processes, such as environmental impact reports. 
impacts of oil (Epstein and Selber 2002) analyzes a broad range of potential health impacts, but it does not examine them in relation to a specific policy decision.

The slow pace of HIA in the United States stands in sharp contrast to the advances the United States has made in the related field of environmental impact analysis, which is widespread and well developed, dating to the passage of the National Environmental Policy Act (NEPA) in 1969. Indeed, the United States was the first nation to pass legislation requiring such environmental review. Subsequently, NEPA has provided a framework for most other nations' environmental impact assessment statutes (Sadler 1996).

As of yet there is no large-scale movement to bring HIA into widespread practice in the United States. Several nonprofit foundations have advocated its use (for example, AARP et al. 2001), but government representatives and agencies have been largely silent on the issue, most notably the Council on Environmental Quality (CEQ) and the EPA - the agencies most directly involved in EIA. One federal agency that has supported initiatives related to HIA is the NIEHS. Although it has not called for HIA per se, the NIEHS has supported initiatives, such as communitybased participatory research and translational research to educate the public and support community involvement in identifying and investigating environmental health concerns (U.S. NIEHS, Division of Extramural Research and Funding 2003). The NIEHS also supported the federal government's study of the health effects of global climate change (Patz et al. 2000), which could be considered an example of an HIA.

Several arguments support the adoption of HIA. First, there is a growing recognition that the health of a population is largely determined by broad determinants including social factors, the physical environment, and economic policies. Thus, it is necessary to address these underlying health determinants if health disparities, and overall disease burden, are to be reduced, as well as to improve health in communities. These determinants are affected by policies that are largely outside the health sector (WHO 1986). They are not usually within the jurisdictions of government health agencies or legislative committees charged with a health agenda. Health impact assessment explicitly addresses these intersectoral issues.

Second, HIA is a flexible tool to bring health issues into policy deliberations in other sectors with strong influences on health. For example, the fastest-growing major epidemic in the United States is the rapid and continuing growth in the frequency of overweight and obesity (U.S. Department of Health and Human Services 2001). Effectively surmounting 
this public health challenge will require changes in multiple sectors that influence both physical activity and nutrition, including community planning, transportation, and agriculture at a minimum. HIA can help policy makers in those sectors understand the likely health effects of policies they are considering.

A third argument for the adoption of HIA is that it provides a systematic method to gather and assess evidence about possible health effects - effects that are of deep and apparently growing concern to Americans (Mellman Group 2002). There has been a sharp increase in interest in systematic reviews of evidence for population health improvement interventions (Judd, Frankish, and Moulton 2001; Speller, Learmonth, and Harrison 1997). A large initiative has been launched under the sponsorship of the Centers for Disease Control and Prevention for systematic evidence reviews of these interventions (Zaza et al. 2000). The U.S. Community Preventive Services Task Force Recommendations is formulating and disseminating recommendations based on these reviews (U.S. Community Preventive Services Task Force 2003). While the task force focuses primarily on activities within the purview of the public health and health care sectors, some of the policy interventions reviewed target changes in the sociocultural environment that involve the actions of other sectors in bringing about improvements in health and reducing health disparities. HIA methods can easily adapt the explicit and reproducible methodologies developed by the task force and other programs for systematic research reviews.

Finally, HIA is a process that can include formal mechanisms for structured input by key stakeholders, thus facilitating a more informed decisionmaking process. Those sponsoring HIA can agree to communicate its methods and findings at critical stages to interested parties for review and comment and then use this feedback to help guide the subsequent analysis and dissemination.

The authors of NEPA recognized the same issue that health planners are concerned with today - that problems in one sector are shaped to a large extent by actions in other sectors (Caldwell 1998). As a result of NEPA and subsequent state laws patterned after it, the assessment and consideration of environmental impacts has become a routine part of decision making in federal, state, and local agencies in the United States across all sectors (ibid.; Eccleston 1999). Given the thirty years of experience with EIA and the interrelated nature of health and the environment, we expected that an examination of EIA would generate information useful to the development of HIA. By identifying the successes and shortcomings of the EIA process, we sought to answer the following questions: 
1. What are the opportunities for integrating a fuller consideration of health impacts into the existing EIA process? What would be the advantages and disadvantages of integration?

2. Could the NEPA-EIA process serve as a model for a similar, but separate, process to assess health impacts? What would be the advantages and disadvantages of such an approach to HIA?

This article addresses the technical feasibility and potential policy lessons for HIA that can be gleaned from EIA - in other words, whether HIA can be done effectively and, if so, what it would entail. We have already briefly outlined some of the arguments for why HIA should be pursued, although the full extent of its value remains to be established. It will vary greatly according to the issue at hand, the quality of information produced given the methodological and resource limitations of HIA, and the valuation of information from HIAs by decision makers and the public. What this article does not address, however, are the how questions, that is, the political and bureaucratic aspects of HIA acceptability, funding, and implementation. These are important issues, but ones that are beyond the scope of this article.

\section{Research Methods}

This examination of EIA practices relevant to HIA weaves together three sources of information - a review of the published literature, an examination of three EIAs, and twenty-one key informant interviews. The focus was primarily on the federal EIA (i.e., NEPA) process and secondarily on California's equivalent legislation, the California Environmental Quality Act (CEQA), considered to be among the strongest of such state laws (Eccleston 1999). Environmental impact assessment policies and practices in other states and nations were considered to a lesser extent, mostly as a counterpoint to NEPA.

Literature on EIA, including reviews, commentaries, and guidance for practitioners, was sought out in books, peer-reviewed journal articles, agency documents, and information from environmental professional organizations. Key documents from the search are cited throughout this article.

Examples of EIA contents and methods were found in the examination of three recent EIAs, all in Southern California, recommended by several of the key informants as particularly comprehensive in their analysis of environmental impacts. These EIAs included the Los Angeles Inter- 
national Airport's Master Plan-EIR/environmental impact statement (EIS; Federal Aviation Administration and Los Angeles World Airports 2001), the Sunshine Canyon Landfill EIR (County of Los Angeles 1997), and the Playa Vista housing development EIR (City of Los Angeles 1993).

The key informant interviews were conducted by telephone with twenty-one environmental professionals involved at various levels of EIA preparation or review. Informed consent for taping the interviews was obtained following the procedures approved by the human research subjects protection committee at the researchers' university. Fourteen openended discussion questions listed in the appendix guided these interviews, which averaged thirty minutes each. A professional transcriber transcribed the interviews, which were then reviewed for accuracy by one of the interviewers.

\section{Description of Interview Respondents and Their Selection}

The interview sample was not selected to be representative of EIA professionals, but to include a range of highly knowledgeable experts in the field who could identify key issues in EIA policies and practice that related to health impacts and their assessment. Fifty-one potential respondents were identified through referrals from the authors' professional contacts, from professional organizations, from authors of EIA reviews found in the literature, and from other respondents (i.e., snowball sampling). Because our goal was to obtain information from a range of EIA experts we tried to get at least three respondents in each of the following categories: public and private sectors, EIA preparer, EIA reviewer, and EIA user. Every effort was made to recruit respondents with the most extensive experience, that is, those recognized by their peers as having the greatest expertise in the field, although the EIA preparers tended to be more junior staff members. In the public sector we also sought to recruit respondents from both regulatory and public works agencies (i.e., agencies that would be proposing projects subject to NEPA).

Altogether twenty-one of the original fifty-one potential respondents were interviewed. Among those not interviewed, four referred us to other individuals in their organizations, four were not available to be interviewed due to scheduling problems, and twenty-two either refused or did not return phone calls. It was particularly difficult to find respondents who would agree to be interviewed from the private sector with the exception of employees of utility companies. 
Table 1 Description of Interview Respondents: Type of EIA Work and Type of Employer

\begin{tabular}{|c|c|c|c|c|c|}
\hline \multirow[b]{2}{*}{ Type of Employer } & \multicolumn{5}{|c|}{ Type of EIA Work } \\
\hline & Preparation & Review & $\begin{array}{l}\text { Preparation } \\
\text { and Review }\end{array}$ & Use & Total \\
\hline Public works/public utility (private) & 1 & 2 & $6[1]$ & & 10 \\
\hline Public resource management & & & 1 & & 1 \\
\hline Regulatory agency & & 3 & & & 3 \\
\hline Private consulting firm & & & 2 & & 2 \\
\hline Law firm & & & & 1 & 1 \\
\hline Advocacy, nonprofit & & & & 2 & 2 \\
\hline University (private) & & 1 & & & 1 \\
\hline Chemical manufacturing (private) & 1 & & & & 1 \\
\hline Total & 2 & 6 & 10 & 3 & 21 \\
\hline
\end{tabular}

Respondents in our purposive convenience sample had an average of 14.5 years of experience in the EIA field. Most of the respondents were quite senior in their work and professional organizations, including division and department heads and executive officers in professional organizations. All but one of the respondents was at least the level of project manager. Six respondents had been involved in the formulation of EIA policies at the state or federal levels. As shown in Table 1, respondents worked in a variety of organizations in three major areas of EIA practice-EIA preparation, review of EIAs by regulatory agencies, and the use of EIAs by stakeholder groups. Included in the sample were EIA preparers working for private consulting companies and public works agencies, reviewers from various regulatory agencies, environmental law attorneys from agencies and environmental advocacy groups, academics, and national board members from a major EIA professional association. The majority of respondents were from California (sixteen out of twenty-one). Of the remaining respondents, three were from federal regulatory agencies on the East Coast, one was from a utility company in another West Coast state, and one was from a private engineering firm on the East Coast.

\section{What Is NEPA?}

With the National Environmental Protection Act of 1969, Congress mandated an innovative approach to compel federal executive branch agencies 
to consider the environmental effects of their actions, a consideration that fell outside the bounds of most agencies' traditional mandates (Caldwell 1998). The one agency whose rule making is generally exempt from NEPA is the EPA, because it is already expected to consider environmental impacts in its rule making. Due to the constitutionally mandated separation of powers, congressional action is also exempt from NEPA.

At the core of NEPA is the requirement to prepare an EIS, which is considered the action-forcing mechanism of the act. The EIS summarizes the findings of an environmental review conducted for a proposed agency action. Although the purpose of NEPA is to "promote efforts which will prevent or eliminate damage to the environment and biosphere" (National Environmental Policy Act of 1969, Public Law 91-190, 91st Cong., sec. 2 [1969]), there is no substantive requirement forcing federal agencies to select a course of action that an EIS identifies as environmentally preferable. The purpose of an EIS is to inform agency decision making by identifying probable environmental impacts and making this information, along with details about the proposed action, available for public scrutiny and debate. By forcing federal agencies to discover and disclose the environmental effects of their proposals, NEPA enables individuals and groups to challenge agency actions through bureaucratic, political, and legal ${ }^{2}$ means. Moreover, since agencies will anticipate these challenges, NEPA is expected to encourage agencies to be more protective of the environment (Caldwell 1998).

State and local governments and private parties may also find themselves subject to NEPA, albeit indirectly, because their proposed projects often require the approval of licenses or permits from federal agencies. For example, a proposed solid waste facility may need approval from the Bureau of Land Management, the Department of Transportation, and the EPA, among others. Granting these licenses and permits is considered an agency action covered by NEPA. In such cases, the concerned agencies will require the party proposing the project to prepare an EIA.

2. Because the requirements of NEPA are procedural, and not substantive, legal challenge in most cases must be based on allegations of procedural failings in the EIS process (Calvert Cliffs v. AEC, 1972). For instance, a community group would not have grounds under NEPA to challenge an agency's action just because it will have substantial negative environmental impacts. The group could, however, challenge an action because the EIS did not adequately review a particular significant impact. 


\section{The Shaping of NEPA Regulations and Standards}

The statute itself is brief and broad, with a limited number of explicit instructions for compliance. More specific guidance for NEPA implementation is provided by the CEQ, ${ }^{3}$ the office in the executive branch charged with overseeing NEPA implementation, and the EPA, which reviews all EISs (see U.S. EPA, 1999 ). Most of this guidance, however, is procedural. Judicial review ${ }^{4}$ has also played a large role in shaping the interpretation and implementation of NEPA procedures (Caldwell 1998; Smith 1992). According to our key informants, informal standards based on common practice also play a large role in determining how NEPA is implemented. Within the broad parameters outlined by NEPA, the CEQ, and the EPA, agencies are generally allowed to develop their own guidance on EIS format and procedures, resulting in rather different approaches to impact assessment (Eccleston 1999).

\section{The NEPA EIA Process}

NEPA implementation is a sequential process (see Figure 1). First, an agency must assess whether a proposed action (e.g., a project, regulation, policy, or issuance of a permit) is subject to NEPA and whether an EIS must be prepared. An EIS must be prepared if the action will "significantly affect the quality of the human environment" (40 Code of Federal Regulations, sec. 1508.14 [1982]). To make this determination agencies often prepare a brief environmental assessment (EA). If an EIS is required, a draft EIS will be prepared by the lead agency (i.e., the agency with the most authority over the project) and be made available for review by the public and other concerned agencies. The comments and a response to them will be included in the final EIS. Then, in the record of decision, the agency will publish its decision, documenting that it has considered the impacts and alternatives analyzed in the EIS and listing any mitigation, monitoring, or enforcement actions to be undertaken. Twenty-five states have mandated similar environmental review procedures in their own state environmental policy acts (SEPAs), with the SEPAs of California, Washington, and New York being considered among the most extensive and stringent (Eccleston 1999).

3. A list of CEQ memoranda on NEPA guidance is available on the Department of Energy's NEPA-net Web site at ceq.eh.doe.gov/nepa/regs/guidance.html.

4. Briefs of important NEPA court cases are available on the Web site of the National Association of Environmental Professionals at www.naep.org/NEPAWG/majorcas.htm. 


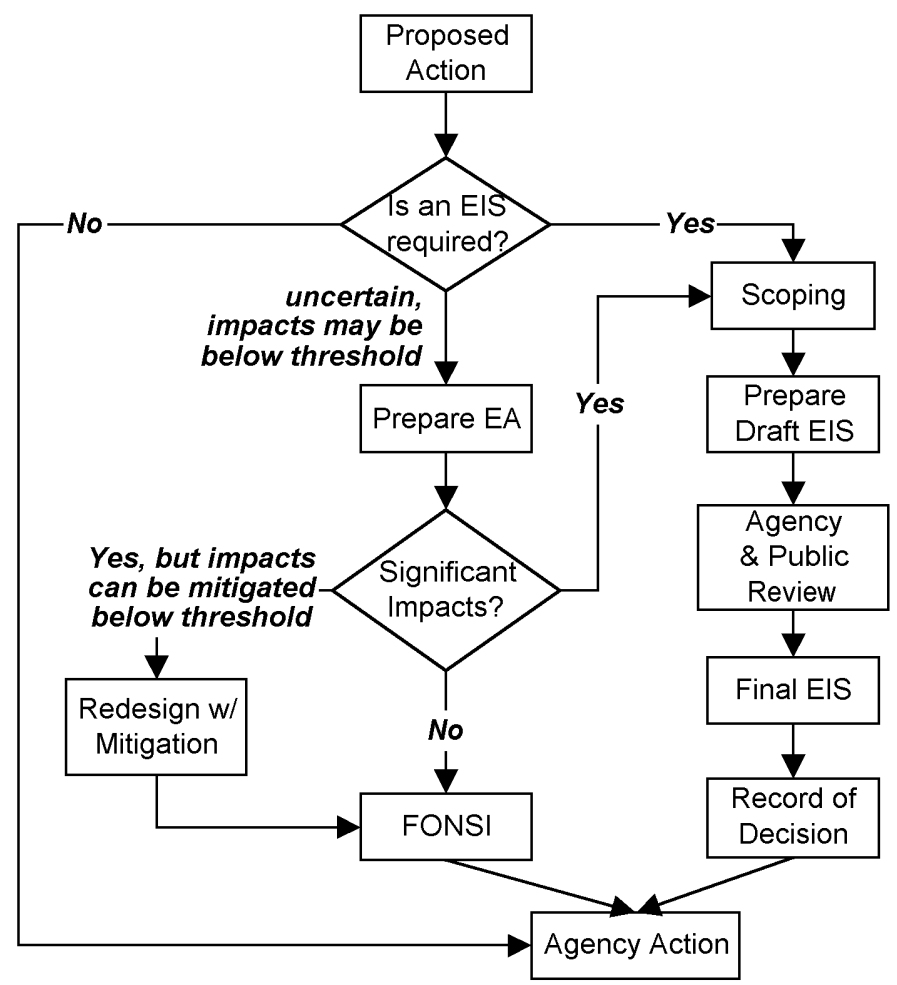

\section{Terms:}

EA: Environmental Assessment (brief)

EIS: Environmental Impact Statement (long, comprehensive) FONSI: Finding of No Significant Impact

ROD: Record of decision documenting EIA and decision process

Scoping: Experts and stakeholders determine scope and issues

Figure 1 Sequence of Environmental Assessment under the National Environmental Policy Act (NEPA)

\section{Preparation of Environmental Impact Statements}

The preparation of an EIS can be extremely time consuming and resource intensive (ibid.). Preparation time and costs vary by agency and project. Although the CEQ recommends that EISs should take a year or less to complete, in practice, often one to two years are required and sometimes substantially longer. For instance, on Department of Energy (DOE) proj- 
ects EIS costs typically range from hundreds of thousands of dollars to several million dollars (U.S. DOE 2000); however, the costs of some EISs are in the tens of millions of dollars for very complex or controversial projects.

Excessive document page length has been a major problem for NEPA implementation. The EPA estimates that only 37 percent of EISs stay within the CEQ guidelines of 150 pages or less (U.S. EPA 2001). Documents may be thousands or even tens of thousands of pages in length since large technical appendices are often used to summarize study methodologies and results.

Due to the complexity and sheer volume of work involved, EISs are usually written by teams, bringing together individuals with expertise in many different areas (e.g., engineering, geology, wildlife, urban planning). Although the lead agency is ultimately responsible for the adequacy and content of an EIS, it can, and often does, use outside contractors to perform the work.

As many as 2,000 EISs were prepared per year in the early 1970s, but this rate has gradually decreased to about 500 EISs prepared per year in the 1990s. In contrast, EAs have evolved from being a relatively insignificant part of NEPA implementation to the predominant form of NEPAmandated EIA, with an estimated 50,000 EAs prepared annually (Council on Environmental Quality 1997a).

Preparation of an EA is far less burdensome to an agency than an EIS. An EA will typically be only a dozen or so pages in length. Alternatives are not considered and the analysis of impacts is usually cursory, without substantial documentation (Eccleston 1999). Unlike EISs, EAs have little, if any, provision for public participation in scoping and review. To avoid the costs and potential delays entailed by public participation, agencies will often try to keep potential impacts (or at least contend that they are) below the threshold of significance requiring a full EIS. Proponents of EAs say their increased use is evidence of a trend toward earlier, more proactive consideration of environmental impacts in project planning and incorporation of mitigation measures in the planning process. Critics contend they circumvent the intent of NEPA, particularly provisions for public involvement in decision making (Council on Environmental Quality 1997a).

\section{EIA Contents-Impacts Considered}

The impacts assessed in an EIA and the methodologies used will vary according to the proposed project, the local environment, and the agencies 
concerned. Although NEPA itself offers no guidance on what specific impacts must be considered in the EIA, other supporting regulations, such as the Clean Air Act (U.S. EPA 1999), specify that certain issues must be addressed in the NEPA compliance process. Standard agency practice offers some guidance.

\section{Limited Consideration of Human Health Effects in EIA}

NEPA-mandated EIAs generally include little, if any, explicit consideration of human health impacts, even though the stated purpose of the act is to protect the "human environment" and "stimulate the health and welfare of man" (NEPA 1979). Among the health-related environmental impacts considered in federal EIAs are impacts on air quality, water quality, and noise, but respondents indicated that the human health effects of these environmental impacts are not addressed. According to the CEQ Regulations for Implementing NEPA, economic and social impacts should be considered only to the extent that they are interrelated with impacts on the physical environment (40 Code of Federal Regulations, sec. 1508.14 [1982]). Most state environmental policy acts, to the extent they consider human health issues, similarly focus on environmental exposures and not health outcomes. Under California's CEQA, some health outcomes and risks are considered, specifically those associated with releases of toxic substances and the risks of catastrophic accidents, both of which are governed by laws setting specific standards (Bass 1999; California Code of Regulations, title 14, chap. 3 [1998]).

The reasons for this restricted scope are practical, methodological, and legal. First, it is more difficult to predict health outcomes than to predict emissions. Analysis of outcomes adds more links to the putative causal chains, with each link requiring more assumptions and leading to increased levels of uncertainty in predictions (Steinemann 2000). Moreover, some causal relations are simply unknown. Second, scientific uncertainty, coupled with a narrow reading of the law, has been the basis for courts restricting the scope of NEPA in cases such as Metropolitan Edison v. People against Nuclear Energy (PANE), 460 U.S. 766 (1983). In the PANE case, the U.S. Supreme Court ruled that potential adverse impacts to human health need only be evaluated under NEPA if there is a "reasonably close causal relationship between a change in the physical environment and the effect at issue" (Metropolitan Edison, 460 U.S. at 778). Specifically, in the PANE case the Court ruled that under NEPA impacts 
on psychological health and community well-being did not need to be considered in an EIS. According to the respondents, agencies avoid considering higher-order effects, such as health impacts, since doing so introduces greater uncertainty, opening the way for legal challenges. Third, there is a clear emphasis in EIAs on impacts governed by specific standards, but few regulatory standards mandate health outcomes. Although environmental health standards may be based on human health risk, the actual standards are expressed in levels of permissible levels of substances in the physical environment. ${ }^{5}$ However, endangered species, wetlands, hazardous waste, air quality, water quality, and archaeological resources are all protected by specific regulations that set clear standards against which impacts may be judged as to their significance. Agencies charged with enforcing these standards are also expected to participate in the EIA scoping and review phases to ensure that impacts within their purview are adequately addressed in the EIA. Impacts not regulated by strict standards generally receive little, if any, attention in an EIS.

Occasionally, EISs address human health impacts, most notably those related to air quality and toxic chemicals. Anne Steinemann's (2000) review of forty-two EISs found that human health effects were assessed in only seven (17 percent of them). The only health effect assessed by these seven was cancer-related mortality due to exposure to a single substance (ibid.). The emphasis on cancer is understandable, given the relatively well-developed understanding of single-substance carcinogenesis, the availability of standardized assays of carcinogenicity, and high levels of societal concern about cancer. Cancer also has regulatory relevance because studies of cancer establish the scientific basis of many environmental health standards (see Powell 1999).

\section{Consideration of Environmental Justice in EIA}

One of the few higher-order social impacts that must be considered in an EIS is environmental justice. Executive Order 12898 (Code of Federal Regulations, 3, 859 [1995]), signed by President Clinton in 1994, requires that EISs prepared in compliance with NEPA take into consideration the impacts of projects on environmental justice. Some states, such as Cali-

5. An exception to this is California's Air Toxics Hot Spots Information and Assessment Act (California Health and Safety Code, sec. 44390 et seq., AB 2588 [Connelly] as amended by SB 1731 [Calderon] [1992]), which sets forth standards in terms of estimates of excess cancer rates attributable to an emission. 
fornia, are also increasingly taking note of environmental justice issues (California Office of Planning and Research 2001). However, according to the respondents we interviewed, a great deal of uncertainty remains about how to operationalize definitions and assessments of environmental justice and related terms, such as community.

\section{Impact Assessment Methodology}

Although the CEQ regulations include specific instructions for the format and content of EA and EIS documents, they provide only a broad framework for how analyses of environmental impacts should be conducted. Federal agencies are required to establish their own internal environmental impact assessment guidelines. It is up to cooperating agencies involved in the interagency EIS review process and the public to debate whether a given method, assumption, or level of analysis presented in an EA or EIS is considered adequate.

Uncertainty abounds in EIA analyses because data are limited and because natural systems are complex and difficult to model and predict. The best EIAs detail the assumptions made in the analyses and make explicit the different kinds of uncertainty surrounding their estimates. Even in the best EIAs, however, information about uncertainty and assumptions may be lost deep in one of the half dozen or so volumes of appendices. Without this information, a false sense of certainty may be communicated. Only one of the three EIAs we reviewed had any substantive discussion of uncertainty - describing the data assumptions in the quantitative models and presenting sensitivity analyses of impacts under different scenarios. This parallels the findings of Bruce Leon (1993), who found that only 7 percent of the EIAs in a random sample of thirty-eight provided measurable predictions with direct evidence supporting those predictions. According to the CEQ there are too few data on the predictions made in EISs to make any broad statements about their accuracy (Council on Environmental Quality 1997a).

\section{Successes of Environmental Impact Assessment}

With no significant disagreement among them, respondents identified three areas in which NEPA has had notable successes: integration of environmental goals into agency decision making, improved planning, and transparency and public involvement for improved agency decision mak- 
ing. These points are similar to those found in other reviews of NEPA. However, an additional success - interagency collaboration, noted in the CEQ's twenty-five-year retrospective (ibid.) — was not mentioned by any of our respondents. Each of these three successes is elaborated in more detail below.

\section{Integration of Environmental Goals into Agency Decision Making}

There is a general consensus that NEPA has had a major effect on internal federal agency procedures for approving new programs and projects. NEPA was groundbreaking in that it forced agencies, regardless of their primary mission, to consider the environmental repercussions of their actions prior to the establishment of media-specific environmental regulations (Caldwell 1998; Council on Environmental Quality 1997a). In many instances, this has meant planning projects that minimize environmental impacts (Council on Environmental Quality 1997a; Solomon, Yonts-Shepard, and Supulski 1997).

\section{Improved Planning}

Even the critics of NEPA among the interviewees expressed the view that NEPA and SEPAs have had a positive impact on planning generally by requiring an earlier, clearer, and more complete conceptualization of project plans and objectives. Projects were said to be designed from the outset to minimize environmental impacts - if possible to bring the potential impacts below the threshold requiring a full EIA or at least minimize impacts in order to reduce the likelihood of criticism and calls for costly and time-consuming project modifications in the EIA review process. Illconceived projects were reportedly more likely to be abandoned in the early planning phases when project details were made available for review by other agencies and the public as part of the EIA process.

\section{Transparency and Public Involvement for Improved Agency Decision Making}

One of the great successes of NEPA has been making detailed information about projects available to the public and other agencies. "NEPA opened up for public scrutiny the planning and decision-making processes of federal agencies, in many cases providing the only opportunity for the 
public to affect these processes" (Council on Environmental Quality 1997a: 17). Even though most respondents acknowledged that the level and quality of public participation in EIA needs to be improved, they also asserted that NEPA has created an opportunity for public review and feedback on projects where previously there was little if any such opportunity. Although increased transparency and public involvement are themselves important achievements, they have also produced better-informed and more responsible agency decision making (ibid.).

\section{Shortcomings of Environmental Impact Assessment}

Respondents identified five shortcomings of NEPA and EIA, in general, relevant to health impact assessment. These shortcomings, which are similar to those identified in other reviews of NEPA (ibid.), include the excessive page length and complexity of EIAs, inadequate and often adversarial public participation, an emphasis on procedure over substance, a focus on projects to the neglect of policies and programs, and only a limited consideration of health impacts. While respondents were openly critical of EIA, and while we could discern little, if any patterns of association between criticisms of EIA and respondents' characteristics, it is quite possible that the nonresponders ( 60 percent) of those contacted may have been more critical of EIA practices. The relative lack of respondents from the private sector, in particular, could have biased some of these results.

\section{EIA Documents Are Long, Complex, and Difficult to Use}

Our key informants all expressed the view that NEPA-mandated EISs and state-mandated EIRs are long, complex, and technical. As a result, they tend to be costly and time consuming to prepare, as well as difficult for decision makers and the public to understand and use (ibid.). Nonetheless, most of these respondents also stated that the length and complexity were necessary to make the EIAs legally defensible, arising in response to past legal challenges and in anticipation of new ones - a view expressed by both EIA reviewers and preparers, as well as regulators and project developers. Including all the technical appendices, EIAs for large projects are often thousands of pages in length. For example, just the consideration of one impact - exhaust from vehicles traveling to and from the sitetotals over one hundred pages in the Draft EIS/EIR for the Los Angeles 
International Airport, with projections of the generation and dispersal of dozens of vehicle exhaust components for four project alternatives under several economic growth scenarios (Federal Aviation Administration and Los Angeles World Airports 2001). At the other extreme, EAs are considerably more concise (often only a few dozen pages), but they have, at best, very limited provisions for public and interagency involvement in scoping and review (Council on Environmental Quality 1997a; Eccleston 1999).

\section{Public Participation Is Limited and Adversarial}

Virtually all of the interviewees regarded public involvement in the EIA process as adversarial. Project proponents and public agency personnel generally saw this as undesirable, whereas respondents from environmental advocacy groups regarded the adversarial process as an outgrowth of inherent conflicts between competing interests. While the EIA process provided a needed forum for expressing their concerns, they felt that real, meaningful participation was limited. Even some respondents from agencies concurred with the environmental advocates' contention that public participation was typically too late and too little to change the course of a project. The CEQ review of NEPA suggests involving the public earlier in the planning process before significant options are foreclosed (Council on Environmental Quality 1997a). In many cases, earlier and more meaningful public participation may also make the process less adversarial, as mitigation measures to address public concerns can be more easily integrated into plans while they are being formulated.

\section{Procedural Not Substantive}

NEPA forces a process but not an outcome (Caldwell 1998; Eccleston 1999). Agencies must assess and document the potential environmental impacts of their actions, but they need not base their decisions on the recommendations of the EIS. As long as the review process has been completed in full compliance with the regulations, NEPA allows an agency to choose any alternative considered in the EIS, even if that alternative has greater environmental impacts than other alternatives. ${ }^{6}$ With its procedural focus, NEPA has no provisions for a legal challenge of EIAs on substan-

6. Selection of the alternative with the least environmental impacts may be required, as is the case when only an EA is prepared instead of the full EIS (Eccleston 1999: 159). Unlike NEPA, some SEPAs may force certain environmentally beneficial action. For instance, California's CEQA requires that mitigation measures be incorporated where feasible (Bass 1999). 
tive grounds (see Calvert Cliffs' Coordinated Committee v. Atomic Energy Commission, 449 F.2d 1109 [D.C. Cir. 1971], cert. denied, 404 U.S. 942 [1972]). For instance, if a community group opposes a project because of concerns about releases of high levels of dust and methane, the merit of those concerns alone would probably be insufficient to halt the project under NEPA. Rather, their legal challenge, at least under NEPA, would probably need to focus on procedural issues, such as how, when, and where public notices were posted. ${ }^{7}$

\section{Focus on Projects, Not Programs and Policies}

While NEPA and CEQ guidelines call for the assessment of environmental impacts of most "major federal actions," including projects, programs, and policies (40 Code of Federal Regulations, sec. 1508.18 [1984]), many informants told us that, in practice, the EIA process is largely geared to assessing the consequences of place-based projects. The CEQ itself has acknowledged that "NEPA is virtually ignored in formulating specific policies and often is skirted in developing programs" (Council on Environmental Quality 1997a: 11). This omission is of concern since the broad, multifaceted effects of programs and policies have greater impacts on both the environment and human health than most brick-and-mortar projects.

One reason for the reluctance to apply EIA to programs and policies may be the relative difficulty of predicting their impacts. Even forming a clear picture of how a policy will be implemented and operationalized can be difficult (ibid.). Predicting the impacts of a brick-and-mortar project, such as an electrical generating plant, is usually more straightforward and involves less uncertainty, because the exact parameters of the project are known from the outset and because data from similar projects in other locations can provide a solid basis for projections of potential impacts from the proposed project. With few data to guide the estimation of impacts stemming from a proposed policy, numerous assumptions must be made, increasing the likelihood of error and opening the way for challenge by opponents.

7. This example was provided by an anonymous key informant from an environmental justice advocacy group. 


\section{Limited Provisions for the Consideration of Health Impacts}

EIAs prepared in compliance with NEPA — as well those prepared under most, but not all, SEPAs - typically consider health-related emissions, such as air pollutants, but not the possible health consequences of those emissions. Reasons for this are methodological, practical, and legal (see EIS Contents-Impacts Considered section). Impacts that do not have a clear, direct link to the biophysical environment, such as psychosocial impacts, are not considered at all (see Metropolitan Edison Co. v. People Against Nuclear Energy, 1983). EIAs emphasize consideration of impacts governed by strong regulations, such as air and water pollution, with less emphasis given to issues such as animal vectors of infectious disease, which are subject to less detailed standards. Even when health impacts are considered, their scope is usually limited to cancer risks, ignoring other outcomes such as nuisance, quality of life, disability, and death (Steinemann 2000).

\section{Arguments for Integrating HIA into Existing EIA}

Incorporation of HIA into the existing EIA process is intuitively appealing for two reasons. First, human health is closely linked to the natural environment. NEPA acknowledges this by declaring the protection of human health as one of its main purposes. While to date there has been only limited consideration of health impacts in NEPA-mandated EIAs, HIA would seem a logical extension of the existing assessment process. Second, the EIA process is a well-established process that effectively cuts across bureaucratic and sectoral boundaries. If the goal is to promote the widespread use of HIA in planning, then incorporation into EIAs may be a path of least resistance.

With few exceptions, our interview respondents supported the idea of integrating HIAs into the existing EIA process. The five areas they suggested for incorporating the assessment of health impacts into EIA were assessment of cumulative impacts, technical guidance and training, development of screening tools, program- and policy-level analyses, and improved methods to assess impacts on environmental justice. 


\section{Cumulative Impacts}

Developing tools and standards for assessing cumulative impacts related to human health would represent a significant, albeit challenging, contribution to the state of the art in EIA. Cumulative impacts include incremental impacts occurring over time, possibly from multiple sources; substances; and pathways (Council on Environmental Quality 1997b). Assessments of cumulative impacts are crucial to understanding health outcomes. The CEQ guidelines mandate the consideration of cumulative impacts in EISs; however, virtually all of the respondents reported that current methods for assessing potential cumulative impacts in EIAs are insufficient. In addition to developing the basic science necessary to advance our understanding of cumulative impacts, advances in applications to predict these impacts will probably involve the development and standardization of computer simulation models. Easy-to-use tools, such as well-designed computer software packages, would greatly aid in the dissemination and adoption of these models.

\section{Technical Guidance and Training}

Several respondents felt that the lack of health training among EIA preparers contributes to the deemphasis of health in EIA. EIAs are typically prepared by generalists working with experts from various engineering and natural science backgrounds due to the statutory emphasis on emissions and exposure levels. Respondents identifying this as a problem suggested offering training and technical support for EIA preparers and reviewers on health issues as a way to facilitate the incorporation of HIA into EIA. On the other hand, it seems unlikely that technical guidance and training alone would change EIAs without regulatory changes that would require greater consideration of health impacts.

\section{Screening Tools}

If HIAs are to be integrated into the existing EIA process, screening tools would be important in determining when an HIA is warranted. Not all projects generate significant health impacts. Before proceeding with an HIA, a determination needs to be made whether that particular project, policy, or program is likely to have health impacts above a certain threshold of significance, similar to what is done with an environmental assessment in the NEPA process, to decide whether to proceed with a full EIS. 
A first step toward this goal would be to establish some general guidelines and criteria for determining thresholds of significance for health impacts. Although only impacts on the biophysical environment can trigger an EIS under the current interpretation of NEPA (see Metropolitan Edison Co. v. People Against Nuclear Energy, 1983), threshold determinations for health impacts would signal when these impacts should also be addressed in an EIS that is already under way.

\section{Program- and Policy-Level Analyses}

Policy-level analysis is particularly important to health impact assessment, since policies may impact a myriad of health determinants in the physical and social environments. Developing tools and standards for assessing these impacts of policies and programs can advance both EIA and HIA by increasing agencies' use and acceptance of such strategic assessments (Sadler 1996). Although many agencies will undoubtedly see expansion of EIA into the policy-making realm as an unnecessary burden, there may be cases where policy EIAs may be seen as a way to head off legal challenges by demonstrating that the agency has made a good-faith effort to look at policy impacts. Nonetheless, significant methodological challenges remain. First among these will be to clearly and precisely describe what a given policy will look like once it is implemented. While such a description may be straightforward in the case of a brick-and-mortar project, at the policy level it can be difficult, requiring a range of assumptions and different scenarios.

\section{Environmental Justice}

There is increasing concern about the distribution of environmental impacts, particularly the disproportionate burden of negative impacts borne by historically disadvantaged groups, such as racial minorities and low-income groups. Since 1995, EISs prepared in compliance with NEPA have been required to take into consideration the impacts of projects on environmental justice. Environmental justice presents an opportunity to bring a greater emphasis on assessing health impacts in EIA, since human health has been a central concern in the environmental justice movement (see Bullard 1993). With its emphasis on distributional equity, environmental justice is an especially appropriate avenue for addressing issues of health inequality. Two of the interviewees indicated that an opportunity exists in California to bring a greater emphasis on human health in EIA 
via environmental justice as the state's environmental quality act, CEQA, may be amended in the near future in response to a lawsuit (Communities for a Better Environment et al. v. California Resources Agency, Sacramento Super. Ct., case no. 00CS 00300, filed May 29, 2001) and in response to new state regulations calling for state agencies to address environmental justice issues (California Government Code, sec. 65040.12; and California Public Resources Code, div. 34, pt. 3, sec. 72000 [1999]). Prospects for incorporation of HIA are especially promising in California, since CEQA already requires some assessment of health impacts, namely those related to hazardous materials and emissions of air, water, and noise pollution (California Code of Regulations, title 14, chap. 3 [1998]).

\section{Arguments for a Freestanding HIA}

A freestanding approach to HIA, whether mandatory or not, would assess health impacts independent of any federal or state-mandated EIA. Although our interview respondents clearly preferred integrating HIA into the existing EIA process, they acknowledged several advantages to a freestanding HIA process. First, it would be easier to focus on substantive issues because it would not come with thirty years of legal baggage that have constrained the application of NEPA. Second, the HIA would not be a small section lost in several thousand pages of an EIA document. A third potential advantage, not mentioned by respondents, is that a freestanding HIA would be free to examine policies, something that agencies have been hesitant to do in EIA. A fourth advantage to a freestanding approach, also not mentioned by respondents, is that the need for an HIA could be determined on the basis of the significance of health impacts. Under current CEQ guidelines, the decision to prepare an EIA hinges on the significance of impacts on the biophysical environment (Code of Federal Regulations, 40, sec. 1508.14 [1984]). Human health effects by themselves are insufficient to trigger an EIA.

The chief recommendation given by respondents for a freestanding HIA was essentially the same as for the integrated EIA-HIA alternativethat HIAs should not be mandatory for all projects, that there should be some type of screening to determine which kinds of projects would need an HIA. Respondents also emphasized that HIAs should reflect the strengths of the EIA process under NEPA and the more progressive state equivalents, such as California's CEQA. This HIA process would include the following elements: 
1. Conducting impact assessment early in the planning phase

2. Involving stakeholders from multiple agencies and the public in scoping to determine which impacts should be assessed

3. Facilitating interagency and public review of the draft assessment

4. Using standardized guidelines to screen actions to determine whether the magnitude of likely impacts justifies the preparation of a formal impact assessment

5. A fair and proportionate consideration of alternatives (a strength of NEPA)

6. Incorporation of mitigation measures where feasible (a strength of California's CEQA)

On the one hand, if freestanding HIAs were mandatory, even in very select cases, a major disadvantage, according to respondents from public agencies and private project developers, is that it would engender resistance, as it would be perceived as another time-consuming and costly obstacle to project approval, duplicating the already burdensome EIA process. On the other hand, a nonmandatory freestanding HIA would be unlikely to be widely adopted. Agencies, especially agencies outside the health sector, would have little incentive to assess the health impacts of their actions. Again, one is reminded that the strength of NEPA is its ability to reach across sectors to get agencies to consider environmental impacts that they would not otherwise consider as part of their decision making.

\section{Conclusion and Recommendations}

\section{Potential Value of HIA}

Despite the many shortcomings of the environmental review process, thirty years of experience with EIA has shown that the rationale underlying EIA, and shared by HIA, is sound - that a systematic review of potential impacts during the planning process can focus the attention of decision makers on issues that they would otherwise deem to be outside their agency's mandate. Of course, the potential benefits of this type of review need to be weighed against the potential costs - the costs of the assessment process, diversion of public and private resources for report preparation and review, increased bureaucratic red tape, and delays in agency decision making. These costs are particularly onerous if, as many critics of EIA contend, the existing EIA process tends to emphasize procedural compliance over substantive action toward social goals. The question that 
will determine the extent to which HIA can garner greater interest and acceptance in the United States is, then, given what is known about the strengths and weaknesses of EIA, how can HIA maximize its potential value while minimizing the costs and limitations of the process?

\section{Lessons from EIA}

(What to Emulate, What to Avoid)

The parallels between HIA and EIA and the extensive knowledge base built over three decades of EIA practice make EIA a natural place to look for lessons to guide the nascent field of HIA. Caution is needed, however, because of technical differences between health and environmental analyses, distinct professional cultures, and the fact that EIA has changed the policy-making landscape in which HIA might be introduced. By becoming so ingrained in the governmental decision-making process, EIA has paved a potential path for HIA to follow, but controversy about its processes and impact raise both questions and obstacles for HIA as a required public process.

Among the positive lessons to be gleaned from EIA, the first is the importance of having a standardized process. Target audiences can then become accustomed to what they can expect and can decide how results fit into their decision-making process. Second, establishing formal but flexible screening criteria for determining whether an impact assessment is warranted helps to focus resources and make better use of the time of decision makers. Third, creating a mechanism for stakeholder input and review can enhance the credibility of the process and contribute useful information.

Increasing opportunities for stakeholder input and review was considered to be among the most important successes of EIA under NEPA by the EIA professionals we interviewed; however, stakeholder participation in HIA might often be more problematic. Since HIA would presumably not be as restricted to place-based projects and policies, the impacts considered would be more diffuse and less geographically bounded, thereby making it more difficult to identify and systematically involve stakeholders.

HIA developers can also learn from the EIA screening systems. Of course, HIA selection criteria will differ from those used in EIA, due to differences in types of interventions and anticipated impacts as well as methodologies. Furthermore, HIA, unlike EIA, is not a mandated process and therefore not subject to the same regulatory constraints. HIA users 
are thus free to consider a broader range of issues. However, because HIA is not mandatory, considerably fewer resources are available to conduct HIAs. Without a place-based focus, there are no obvious sources of private funding for HIAs, such as permit fees from developers proposing a project, to partially underwrite assessment costs.

Nearly all survey respondents supported the goal behind HIAincreasing the degree to which health impacts are considered in agencies' decision making. Several respondents saw advantages to HIA separate from EIA, but most respondents tended to view a consideration of health impacts as a logical extension of the existing EIA process. This opinion is not surprising because all of the respondents are environmental professionals heavily invested in the EIA. With an average of almost fifteen years in the EIA field, most have built their entire careers on EIA practice, and several have played key roles in formulating federal and state EIA policies.

Many respondents expressed the concern that an across-the-board requirement for HIAs could become just another bureaucratic hurdle to decision making, producing "more paper but not better decisions" (see 40 Code of Federal Regulations, sec. 1500.1 [1982]). They strongly emphasized that HIAs should be done only when (1) health impacts were expected to be significant and (2) the HIA would produce enough additional useful information to justify the additional investment of time and money. These considerations emphasize the importance of accurate screening criteria for determining when HIAs should be performed.

\section{Potential Collaboration and Overlap between HIA and EIA}

HIA reports (e.g., Patz et al. 2000; Bhatia and Katz 2001) and HIA-like analyses (e.g., Hammitt et al. 1999; Rice et al. 1999; Ponce et al. 2000; Shaffer and Korn 2002) are beginning to emerge in the literature. While these reports generally support HIA feasibility, work remains to be done to identify the appropriate boundaries for HIA. To date there are too few examples of full HIAs on policies within the United States to better define limits and gauge potential benefits against costs.

One option for promoting the use of HIA is to incorporate it into EIA when projects, programs, or policies subject to NEPA are likely to have significant health impacts. However, such an effort could run afoul of the many judicial rulings and administrative regulations restricting the scope of EIAs. In these instances, it might be easier to have a companion but separate HIA, using its own methods. 
For HIA to advance, whether as part of or separate from EIA, demonstration HIAs conducted on a nonmandatory basis can help in several respects. First, they can aid in the development and testing of methods for HIAs in real-world situations. Even in Britain, where significant strides have been made to integrate HIA into planning, concerns are being raised that HIA is insufficiently robust, tried, and standardized (Parry and Stevens 2001). ${ }^{8}$ Second, demonstration HIAs can help determine the range of situations in which HIA is feasible and most useful. Third, dissemination of these HIA results can increase awareness of the potential value of HIA among policy makers and the public, as well as advancing recognition of the broad, intersectoral determinants of health. Fourth, actually conducting HIAs, and not just theorizing about them, will begin to flesh out resource and time costs and weigh their value for agencies, stakeholders, and the general public.

\section{Prospects for HIA in the United States- Including Lessons from Other Countries}

While the United States lags behind some other developed countries in the implementation of HIA, there have been increasing calls for conducting HIA in the United States. Interest has been particularly strong in the areas of transportation and land-use planning, as evidenced by journal articles (e.g., Dannenberg et al. 2003; Northridge and Sclar 2003) and the themes of national conferences, such as the recent national conference on smart growth titled "Building Safe, Healthy and Livable Communities" (New Partners for Smart Growth 2004) and the symposium "Public Health in Land Use Planning and Community Design" cosponsored by the National Association of County and City Health Officials and the American Planning Association (2004).

A comprehensive analysis of the factors that gave rise to support for HIA in countries where it has seen substantial use is beyond the scope of this article. However, even a cursory review of international experience provides lessons with applicability to advancing HIA in the United States. First, the countries in which HIA has gained more support, such as

8. Given the adversarial and litigious nature of policy making in the United States, it could be argued that the need for a sound scientific foundation for HIA is even stronger here than in the United Kingdom. Of course, this begs the question of whether scientific information really impacts policy. However, the real point of NEPA is not to ensure that government decisions are based on scientific evidence, but rather to ensure that evidence of probable significant impacts is available to decision makers and the public. 
Canada, the United Kingdom, and Australia, have also emphasized prevention (Freeman 1995) and principles of population health (Glouberman and Millar 2003; Lavis 2002; Szreter 2003) in political discourse about public health. Second, successful initiatives in support of HIA have tended to follow major public health initiatives that have raised issues HIA could potentially address, such as the Acheson report on inequalities in the United Kingdom.Third, mandated HIA, such as in New Zealand (New Zealand Ministry of Health 1998) and Australia (Tasmania Department of Health and Human Services, 2002), tends to be coupled with existing requirements for EIA. We are unaware of any national mandated for freestanding HIA, although in some cases local governments, such as the City of London, have taken steps to bring HIA into the decision-making process for considerations involving major projects (Abba 2002).

In the United States, the traditional individualistic bias coupled with slower adoption of policies supporting improved population health has created less momentum for HIA with its broad, environmental, and preventive approach to improving health. So much of the energies of the public health community are devoted to problems involving medical treatment - health care financing and uninsurance - problems that are far less pressing in countries where HIA has gained more interest. Nevertheless, there is growing interest and many potential opportunities for HIA in the United States. Among those high-potential targets are intersectoral efforts to reduce overweight and obesity and the effects of tax policies on the health of the entire population and on health disparities among subgroups. Even within the health care sector, there are important opportunities to assess the health benefits and adverse effects of different health insurance systems and increasing access to care for the uninsured.

We can also learn from other models of intersectoral government review besides EIA. In the United States, for instance, analysis of proposed federal legislation is offered by the Congressional Research Service (U.S. Congressional Research Service n.d.) and the Congressional Budget Office (U.S. Congressional Budget Office n.d.) and by state legislative analysts' offices in the majority of states. While the Congressional Budget Office and state legislative analysts' offices tend to focus on the fiscal aspects of pending legislation, their analyses reach across sectoral boundaries to provide credible, high-quality information for policy makers. HIA, or at least screening for HIA, could be coupled to one of these existing mechanisms for legislative analysis in order to identify proposed legislation. 


\section{Next Steps-Including Getting the Most out of Demonstration Projects}

Clearly, the growth and development of HIA in the United States would be enhanced if a government health agency, such as the Centers for Disease Control and Prevention, committed funding to demonstrate how a mandatory HIA process could inform policy making at the national level. NEPA was enacted in the 1970s because of broad public recognition that environmental threats were significant and could no longer be ignored. Because of recent world events, there may be broader public support for protecting public health and personal safety than at any other time in the past century. Although HIA does not directly address security concerns, public awareness of the importance of public health could be leveraged to promote efforts to assess public health and safety, broadly defined, including techniques such as HIA. A mandate would bring the resources necessary to conduct HIA, provide an impetus to improve methodologies, and help standardize procedures, effects similar to EIA mandated under NEPA. In this time when many elected officials and the voting public favor smaller, leaner, less intrusive government, mandated HIA may be a difficult notion to sell outside the public health field. These sentiments could be altered by demonstration of the value of HIA in selected circumstances. If nothing else, HIA is a helpful educational tool to help policy makers understand how and how much their decisions in other sectors can affect the health of their constituents. These demonstration HIAs can then be used to make the case to the public and to decision makers that more concerted effort and investment is needed, including mandated HIA. 


\section{Appendix: Interview Questions}

1. In what capacities have you been involved with environmental impact assessment (EIA)? And for how many years?

2. Could you describe the availability and quality of data to support EIAs? Which areas and concerns have better data? Which have less?

3. What distinguishes a high-quality EIA from a low-quality one? (Examples?)

4. What are the strong points of EIA methodology and what are the weak points?

5. To what extent are standardized methods for EIAs prescribed by the various agencies involved? How are these standards communicated with those preparing assessments?

6. How important are standardized methods in establishing the credibility of EIA?

7. In what ways do EIAs help or hinder the decision-making process?

8. How could the EIA process be improved so that it is more useful to policy makers and other decision makers?

In our project we are examining the feasibility of establishing health impact statements as a tool for policy makers to evaluate the potential health impacts of major projects, policy initiatives, and proposed legislation. These would probably address a broader range of human health issues than are presently considered in EISs and EIRs.

9. How broad of a range of human health impacts are considered in EIAs? What kinds of health impacts are typically considered in an EIA? Which are typically not considered?

10. What measures are used in EIAs to assess these health impacts (e.g., cancer or other disease rates, mortality rates, injury rates, years of life lost)?

11. Why aren't health impacts considered more extensively in EIAs?

12. Have you come across an EIR or EIS that had a particularly comprehensive assessment of health impacts? If so, what was it?

13. What would you say are the pluses and minuses of developing health impact assessment as a freestanding process separate from EIAs versus integrating it into the EIA process?

14. What successes from EIA should be applied in developing health impact assessments? What failures should be avoided? 


\section{References}

Abba, K. 2002. Briefing Paper on Health Impact Assessment. Islington Public Health Department. www.candihps.com/downloads/pdfs/students/briefing\%20on\%20hia .pdf.

American Association of Retired Persons, American College of Sports Medicine, American Geriatrics Society, Centers for Disease Control and Prevention, National Institute on Aging, and Robert Wood Johnson Foundation. 2001. National Blueprint: Increasing Physical Activity among Adults Aged 50 and Older. Princeton, NJ: Robert Wood Johnson Foundation. www.rwjf.org/publications/other.jsp.

Ashton, J. 1991. The Healthy Cities Project: A Challenge for Health Education. Health Education Quarterly 18: 39-48.

Bass, R. E., A. I. Herson, and K. M. Bogdan. 1999. CEQA Deskbook: A Step-by-Step Guide on How to Comply with the California Environmental Quality Act. 2nd ed. Point Arena, CA: Solano Press Books.

Bhatia, R., and M. Katz. 2001. Estimation of Health Benefits from a Local Living Wage Ordinance. American Journal of Public Health 91: 1398-1402.

Birley, M. H. 1995. Health Impact Assessment of Development Projects. London: HMSO. www.liv.ac.uk/ mhb/publicat/pubs1.htm.

British Medical Association. 1998. Health and Environmental Impact Assessment: An Integrated Approach. London: Earthscan.

Bullard, R. D., ed. 1993. Confronting Environmental Racism: Voices from the Grassroots. Boston: South End.

Caldwell, L. K. 1998. The National Environmental Policy Act: An Agenda for the Future. Bloomington: Indiana University Press.

California Office of Planning and Research. 2001. Announcements from the State Clearinghouse - Summer, CEQA Update. www.opr.ca.gov/clearinghouse/summer 2001.shthl.

Canter, L. 1998. Integration of HIA and EIA. EIA Newsletter 16. Manchester: University of Manchester. www.art.man.ac.uk/EIA/nl16.htm.

City of Los Angeles. 1993. Playa Vista Phase 1: Final EIR. Los Angeles: City of Los Angeles.

Council on Environmental Quality, Executive Office of the President. 1997a. The National Environmental Policy Act: A Study of Its Effectiveness after Twenty-Five Years. Washington DC: Council on Environmental Quality.

1997b. Considering Cumulative Effects under the National Environmental Policy Act. Washington, DC: Council on Environmental Quality.

County of Los Angeles. 1997. Sunshine Canyon Subsequent Environmental Impact Report. Los Angeles: County of Los Angeles.

Dannenberg, A. L., R. J. Jackson, H. Frumkin, R. A. Schieber, M. Pratt, C. Kochtitzky, and H. H. Tilson. 2003. The Impact of Community Design and Land-Use Choices on Public Health: A Scientific Research Agenda. American Journal of Public Health 93: $1500-1508$.

Eccleston, C. H. 1999. The NEPA Planning Process: A Comprehensive Guide with an Emphasis on Efficiency. New York: Wiley and Sons. 
Epstein, P. R., and J. Selber, eds. 2002. Oil: A Life Cycle Analysis of Its Health and Environmental Impacts. Center for Health and the Global Environment, Harvard Medical School. www.med.harvard.edu/chge/fullreport.pdf.

Federal Aviation Administration and Los Angeles World Airports. 2001. Joint Draft Environmental Impact Statement/Environmental Impact Report. www.laxmaster plan.org/publications/eis_eir.html.

Fehr, R. 1999. Environmental Health Impact Assessment: Evaluation of a Ten-Step Model. Epidemiology 10: 618-625.

First International Conference on Health Promotion. 1986. The Ottawa Charter for Health Promotion. Health Promotion 1: iii-v.

Freeman, R. 1995. Prevention and Government: Health Policy Making in the United Kingdom and Germany. Journal of Health Politics, Policy and Law 20: 745-765.

Glouberman, S., and J. Millar. 2003. Evolution of the Determinants of Health, Health Policy, and Health Information Systems in Canada. American Journal of Public Health 93: 388-392.

Hammitt, J. K., E. S. Belsky, J. I. Levy, and J. D. Graham. 1999. Residential Building Codes, Affordability, and Health Protection: A Risk-Tradeoff Approach. Risk Analysis 19: 1037-1058.

Health Canada. 2000. The Canadian Handbook on Health Impact Assessment. Ottawa, Canada: Health Canada. www.hc-sc.gc.ca/ehd/oeha/hia.

Ison, E. 2000. Section 6: Models of Health Impact Assessment. In A Resource for Health Impact Assessment. London: National Health Service Executive. www.doh .gov.uk/london/rfhia6.pdf.

Judd, J., J. Frankish, and G. Moulton. 2001. Setting Standards in the Evaluation of Community-based Health Promotion Programmes - A Unifying Approach. Health Promotion International 16: 367-380.

Lavis, J. N. 2002. Ideas at the Margin or Marginalized Ideas? Nonmedical Determinants of Health in Canada. Health Affairs 21: 107-112.

Leon, B. F. 1993. Survey of Analyses in Environmental Impact Statements. In Environmental Analysis: The NEPA Experience, ed. S. G. Hildebrand and S. G. Cannon, 653-659. Boca Raton, FL: Lewis.

Mellman Group. 2002. Memo to Trust for America's Health on the National Survey on Public Perceptions of Risk from Bioterrorism and Other Health Threats. healthyamericans.org/newsroom/surveymemo0515.pdf.

Minnesota Health Improvement Project. 2002. Health Impact Assessment: A Review of the Literature. www.health.state.mn.us/divs/chs/mhip/.

National Association of County and City Health Officials and the American Planning Association. 2004. Symposium on Land Use and Health, Washington, DC, February $19-20$.

New Partners for Smart Growth. 2004. Third Annual New Partners for Smart Growth: Building Safe, Healthy, and Livable Communities, Portland, OR, January 22-24.

New Zealand Ministry of Health. 1998. A Guide to Health Impact Assessment. Dunedin, New Zealand: Ministry of Health Publications. 210.48.125.104/moh.nsf/ wpg_Index/Publications-Index.

Northern and York Public Health Observatory. 2001. An Overview of Health Impact Assessment. Occasional Paper No. 1. www.nypho.org.uk/files/OC01.pdf. 
Northridge, M. E., and E. Sclar. 2003. A Joint Urban Planning and Public Health Framework: Contributions to Health Impact Assessment. American Journal of Public Health 93: 118-121.

Parry, J., and A. Stevens. 2001. Prospective Health Impact Assessment: Pitfalls, Problems, and Possible Ways Forward. British Medical Journal 323: 1177-1182.

Patz, J. A., M. A. McGeehin, S. M. Bernard, K. L. Ebi, P. R. Epstein, A. Grambsch, D. J. Gubler, P. Reither, I. Romieu, J. B. Rose, J. M. Samet, and J. Trtanj. 2000. The Potential Health Impacts of Climate Variability and Change for the United States: Executive Summary of the Report of the Health Sector of the U.S. National Assessment. Environmental Health Perspectives 108: 367-376.

Ponce, R. A., S. M. Bartell, E. Y. Wong, D. LaFlamme, C. Carrington, R. C. Lee, D. L. Patrick, E. M. Faustman, and M. Bolger. 2000. Use of Quality-Adjusted Life Year Weights with Dose-Response Models for Public Health Decisions: A Case Study of the Risks and Benefits of Fish Consumption. Risk Analysis 20: 529-542.

Powell, M. R. 1999. Science at EPA: Information in the Regulatory Process. Washington, DC: Resources for the Future.

Rice, G., B. Boutin, M. Brown, R. Clark, J. Lipscomb, R. Miltner, L. Papa, R. Rheingans, J. Cohen, P. Murphy, T. Harvey, and L. Teuschler. 1999. Methodology for Comparing Risks, Benefits, and Financial Costs of Environmental Health Options. Paper presented at the 1999 Annual Meeting of the Society for Risk Analysis, Atlanta, Georgia, December 5-8, 1999. Abstract: www.riskworld.com/abstract/ 1999/SRAam99/abab9ab287.htm. Full report: www.epa.gov/ncea/frame.htm.

Sadler, B. 1996. Environmental Assessment in a Changing World. International Study of the Effectiveness of Environmental Assessment, Final Report. Ottawa: Canadian Environmental Assessment Agency.

. 1998. Incorporating Health Considerations into EIA. EIA Newsletter 16. Manchester, UK: University of Manchester. www.art.man.ac.uk/EIA/nl16.htm.

Shaffer, H. J., and D. A. Korn. 2002. Gambling and Related Mental Disorders: A Public Health Analysis. Annual Review of Public Health 23: 171-212.

Signal, L., and G. Durham. 2000. Health Impact Assessment in New Zealand Policy Context. Social Policy Journal of New Zealand 15: 11-26.

Smith, J. L. 1992. Consideration of Socioeconomic Effects under NEPA and the EC Directive on Environmental Impact Assessment. University of Chicago Legal Forum, 355-375.

Solomon, R. M., S. Yonts-Shepard, and W. T. Supulski. 1997. Public Involvement under NEPA: Trends and Opportunities. In Environmental Policy and NEPA: Past, Present, and Future, ed. R. Clark and L. Canter. Boca Raton, FL: St. Lucie.

Speller, V., A. Learmonth, and D. Harrison. 1997. The Search for Evidence of Effective Health Promotion. British Medical Journal 315: 361-363.

Srinivasan, S., L. O'Fallon, and A. Dearry. 2002. Built Environment-Healthy Communities, Healthy Homes, Healthy People. Final Report, July 15-16. Research Triangle Park, NC: National Institute of Environmental Health Sciences. www.niehs .nih.gov/translat/BE-final.pdf.

Steinemann, A. 2000. Rethinking Human Health Impact Assessment. Environmental Impact Assessment Review 20: 627-645. 
Szreter, S. 2003. The Population Health Approach in Historical Perspective. American Journal of Public Health 93: 421-431.

Tasmania Department of Health and Human Services. 2002. Health Impact Assessment. www.dhhs.tas.gov.au/publichealth/legislationandguidelines/healthimpact .html.

Tesh, S. 1988. Hidden Arguments: Political Ideology and Disease Prevention Policy. New Brunswick, NJ: Rutgers University Press.

U.S. Community Preventive Services Task Force. 2003. The Guide to Community Preventive Services. www.thecommunityguide.org.

U.S. Congressional Budget Office. n.d. Mission. www.cbo.gov/Mission.cfm (accessed January 20, 2004).

U.S. Congressional Research Service. n.d. About CRS. www.loc.gov/crsinfo/whatscrs .html (accessed January 20, 2004).

U.S. Department of Energy. 2000. NEPA Document Cost and Completion Time Facts. Lessons Learned 24: 20-21. tis.eh.doe.gov/nepa/process/11/2000SeptLLQR.pdf.

U.S. Department of Health and Human Services. 2001. The Surgeon General's Call to Action to Prevent and Decrease Overweight and Obesity. Rockville, MD: U.S. Department of Health and Human Services, Public Health Service, Office of the Surgeon General.

U.S. Environmental Protection Agency. 1999. EPA's Section 309 Review: The Clean Air Act and NEPA. es.epa.gov/oeca/ofa/brochure.html.

— 2001. EPA Office of Federal Activities, EIS Page Lengths, August 10. es.epa .gov/oeca/ofa/length.html.

U.S. National Institute of Environmental Health Sciences, Division of Extramural Research and Funding. 2003. Translational Research. www.niehs.nih.gov/translat.

World Bank. 1997. Health Aspects of Environmental Assessment. Environmental Assessment Sourcebook Update, number 18. Washington, DC: World Bank.

World Health Organization. 1986. Ottawa Charter on Health Promotion. Charter presented at First International Conference on Health Promotion, Ottawa, November 21. www.who.int/hpr/archive/docs/ottawa.html.

- 1999. Health Impact Assessment: Main Concepts and Suggested Approach. Gothenberg Consensus Paper. Copenhagen, Denmark: WHO Regional Office for Europe. www.who.dk/hs/ECHP/index.htm.

Zaza, S., R. S. Lawrence, C. S. Mahan, M. Fullilove, D. Fleming, G. J. Isham, and M. Pappaioanou. 2000. Scope and Organization of the Guide to Community Preventive Services: The Task Force on Community Preventive Services. American Journal of Preventive Medicine 18: 27-34. 